\title{
A RADIOCARBON AGE CALCULATION PROGRAM FOR WINDOWS
}

\author{
D Gallagher ${ }^{1} \bullet$ E J McGee • P I Mitchell \\ Department of Experimental Physics, University College Dublin, Belfield, Dublin 4, Ireland
}

\section{INTRODUCTION}

The management of counting files, the calculation of radiocarbon age, and the creation and maintenance of databases for storage and retrieval of laboratory data are time-consuming and exacting tasks. These routine functions are essential to the successful operation of all ${ }^{14} \mathrm{C}$ dating laboratories. However, since the number of ${ }^{14} \mathrm{C}$ dating laboratories worldwide is rather limited, it is unlikely that a commercial software company will produce a program for use in ${ }^{14} \mathrm{C}$ age calculation and associated data management. We have therefore developed Windows based software to meet some of these needs. The program described here offers a user-friendly interface to assist with:

- Execution of age and error calculations

- Reducing the possibility of human error during the lengthy age calculation procedure

- Developing a single entry system that simultaneously runs dating algorithms and compiles a database of all samples processed by a laboratory.

We now make the program and the program code available to the ${ }^{14} \mathrm{C}$ dating community. We hope that this program will be a useful tool in routine laboratory operation and can be further developed in the future.

\section{PROGRAM DESIGN}

The program is designed for use by conventional radiometric laboratories. It is written in Visual Basic 6.0 for Windows operating systems. The program manages the data output formats of both Quantulus and Tri-Carb liquid scintillation counters. The operator enters all essential data relating to a sample in a Windows screen (identification codes, mass of sample, counting geometry, $\delta^{13} \mathrm{C}$ value, etc.), directs the program to the relevant counting files (for sample, standard and background) and specifies the method of age calculation to be applied.

The program then uses standard algorithms (Stuiver and Polach 1977) to calculate conventional ${ }^{14} \mathrm{C}$ age, $\mathrm{pMC}$ value (with or without $\delta^{13} \mathrm{C}$ correction), and associated error estimates (error calculation procedures are detailed on our webpage).

Data that are entered to the program, together with results generated by program algorithms are automatically sent to a Microsoft Access database. This facilitates the maintenance of records and provides a flexible search system for subsequent retrieval of stored information using sample codes or keywords. Entering a previously used sample code to the main age calculation program will automatically recall sample details from the Access database, thus facilitating the tracking, checking and re-calculation of sample age. In addition, all data essential for reporting are compiled to a Microsoft Word or text document in layout suitable for dispatch to the submitter.

The program is laid out (Figure 1) so that all details concerning a sample are immediately visible, and this transparency and ease of checking helps reduce the possibility of calculation errors.

${ }^{1}$ Corresponding author. Email: Donal.Gallagher@ucd.ie. 


\section{ACCESSING AND USING THE PROGRAM}

An executable version of the program can now be downloaded from our website at www.ucd.iel $\sim$ 14. The program code in Visual Basic, and the instructions manual in Adobe Acrobat format are also available on the site. Some example files are included to assist with learning the operation of the program. However, by designing the program in Windows format it has been possible to create data entry and output forms in clear and intuitive layout - the functions can be quickly understood and the program is simple to use.

\section{DEVELOPMENT AND FEEDBACK}

It is intended that the program can be improved and developed, based on feedback from other ${ }^{14} \mathrm{C}$ laboratories. Users of the program are invited to send suggestions and comments that will help us improve layout and function. Full access to the program code gives all laboratories a Windows based foundation from which they may proceed to tailor the program to meet their own needs. There is also considerable scope for further developing program routines (e.g. to interface output with calibration programs). It is anticipated that any laboratory that creates an additional routine for the program will make the code available for distribution to the wider community.

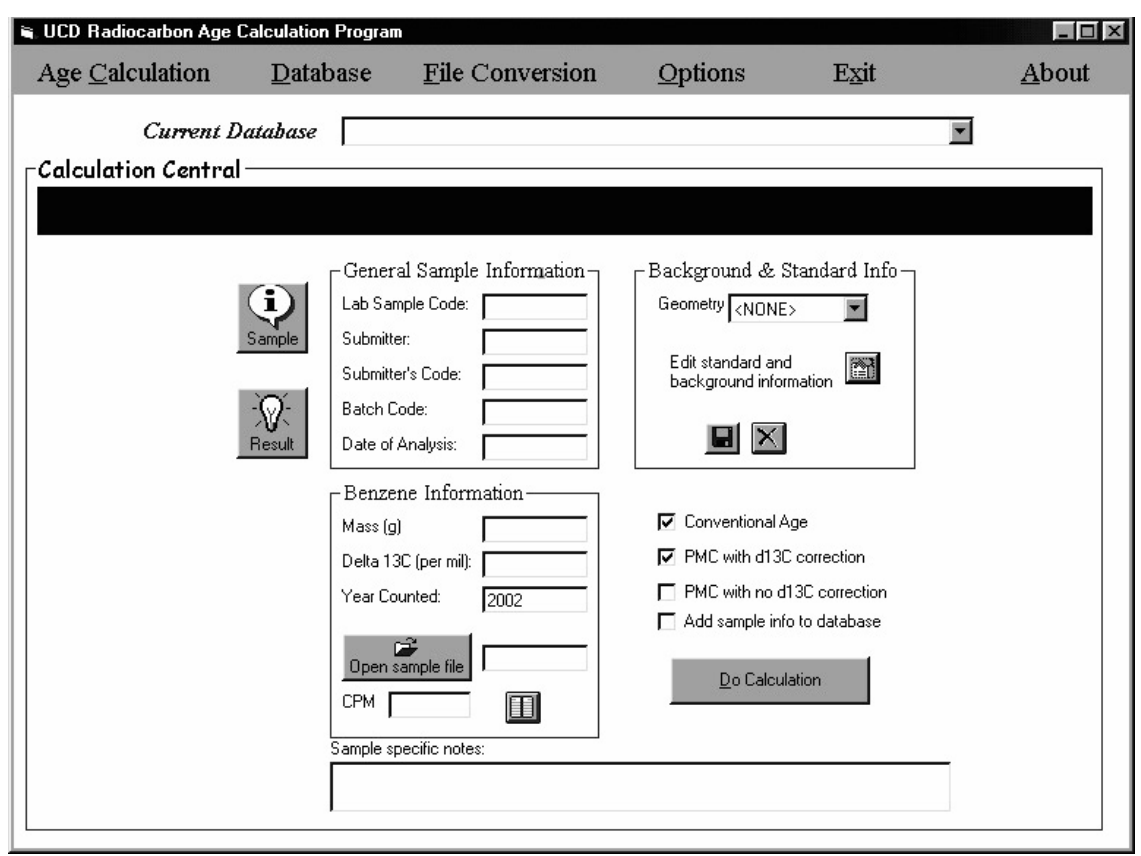

Figure 1 Illustration of the front page of the age calculation program showing the layout and the main features accessible in the program

\section{ACKNOWLEDGMENTS}

Our thanks to Kilian Smith for work on our website development. Also to Gordon Cook of the Scottish Universities Research Reactor Centre and Elisabetta Boaretto of the Weizmann Institute, Israel for testing the program.

\section{REFERENCE}

Stuiver M, Polach HA. 1977. Discussion: reporting of ${ }^{14}$ C data. Radiocarbon 19(3):355-63. 